\title{
Relationships Between Animal Health Monitoring and the Risk Assessment Process
}

\author{
By K.D.C. Stärk', and M.D. Salman ${ }^{2}$ \\ ${ }^{1}$ Danish Bacon and Meat Council, Copenhagen, Denmark, and ${ }^{2}$ Department of Environmental Health, College \\ of Veterinary Medicine and Biomedical Sciences, Colorado State University, Fort Collins, Colorado, U.S.A.
}

\begin{abstract}
Risk assessment is part of the risk analysis process as it is used in veterinary medicine to estimate risks related to international trade and food safety. Data from monitoring and surveillance systems (MO\&SS) are used throughout the risk assessment process for hazard identification, release assessment, exposure assessment and consequence assessment. As the quality of risk assessments depends to a large extent on the availability and quality of input data, there is a close relationship between MO\&SS and risk assessment. In order to improve the quality of risk assessments, MO\&SS should be designed according to minimum quality standards. Second, recent scientific developments on state-of-the-art design and analysis of surveys need to be translated into field applications and legislation. Finally, knowledge about the risk assessment process among MO\&SS planners and managers should be promoted in order to assure highquality data.
\end{abstract}

Risk assessment, data quality, disease monitoring, disease surveillance, survey design, animal health.

\section{Introduction}

Risk assessment is part of the risk analysis process, which also includes risk management and risk communication. Risk assessment in veterinary medicine is mainly used to estimate risks related to international trade and food safety. Risk in the risk analysis context is defined as the probability of an adverse event and the magnitude of the consequences (Kaplan \& Garrick 1981, Ahl et al. 1993). The objective of risk assessment is to estimate both these elements in order to provide input to an underlying decision problem, for example: whether or not to permit the import of a certain commodity. A risk assessment is expected to take into account all available information, to systematically structure and analyse it and to provide a scientifically sound, objective outcome. All steps of a risk assessment need to be documented in a transpar- ent fashion such that the results are understandable and reproducible (Wooldridge 1996).

One of the limitations of risk assessment, however, is the lack of reliable and high-quality data that can be used as input (Covello \& Merkhofer 1993, Salman \& Ruppanner 1999). Furthermore, biases introduced by sub-optimal data collection procedures or inadequate data processing and analysis can reduce the accuracy of risk estimates (Covello \& Merkhofer 1993).

Input data for risk assessments can be obtained from disease monitoring systems. Disease monitoring is defined as routine recording, analysis and distribution of data related to health or disease of a defined population in a defined area at a specific point in time (Christensen, submitted). Disease surveillance is a special case of monitoring where pre-defined 
Table 1. Input data for risk assessments provided through animal disease monitoring and surveillance systems

\begin{tabular}{|c|c|c|}
\hline \multirow{2}{*}{ Risk assessment step } & \multicolumn{2}{|c|}{ Input provided through monitoring and surveillance systems } \\
\hline & Animal trade risk assessment & Food safety risk assessment \\
\hline \multirow[t]{2}{*}{ Hazard identification } & Occurrence of risk indicators & Occurrence of risk indicators \\
\hline & $\begin{array}{l}\text { Level and quality of detection } \\
\text { of the agent/disease in an animal } \\
\text { population }\end{array}$ & $\begin{array}{l}\text { Level and quality of detection } \\
\text { of the agent in an animal or product }\end{array}$ \\
\hline \multirow[t]{3}{*}{ Release assessment } & $\begin{array}{l}\text { Prevalence/incidence of agent or } \\
\text { disease in exporting country }\end{array}$ & $\begin{array}{l}\text { Prevalence of agent or substance } \\
\text { at all points of the production system }\end{array}$ \\
\hline & Strain differences if applicable & $\begin{array}{l}\text { Detection level of the agent } \\
\text { at each point of production }\end{array}$ \\
\hline & $\begin{array}{l}\text { Level and quality of detection of } \\
\text { the disease on a population basis }\end{array}$ & \\
\hline \multirow[t]{4}{*}{ Exposure assessment } & \multirow{2}{*}{$\begin{array}{l}\text { Prevalence/incidence of agent or } \\
\text { disease in importing country } \\
\text { (endemic level of the agent in } \\
\text { the host population) }\end{array}$} & $\begin{array}{l}\text { Prevalence of agent or substance } \\
\text { in products }\end{array}$ \\
\hline & & $\begin{array}{l}\text { Prevalence of agent or substance } \\
\text { in the environment (water, air) }\end{array}$ \\
\hline & $\begin{array}{l}\text { Prevalence of agent in the } \\
\text { environment (water, air, wildlife) }\end{array}$ & $\begin{array}{l}\text { Human behaviour and consumption } \\
\text { patterns }\end{array}$ \\
\hline & Strain differences if applicable & \\
\hline \multirow[t]{3}{*}{ Consequence assessment } & \multirow{2}{*}{$\begin{array}{l}\text { Associated risk factors for } \\
\text { the spread of the disease }\end{array}$} & Incidence of human cases \\
\hline & & Severity of human cases \\
\hline & $\begin{array}{l}\text { Economic parameters that are } \\
\text { affected by the exposure to or } \\
\text { introduction of the disease }\end{array}$ & Cost of human cases \\
\hline
\end{tabular}

action will be taken as soon as a specified threshold is passed. Therefore, surveillance is always part of a disease control programme. For exotic diseases, the threshold value to initiate action is typically zero, i.e. there will be eradication measures taken as soon as the first case is diagnosed.

The objective of this article is to elaborate the relationship between monitoring and surveillance systems (MO\&SS) and risk assessment. The requirements to be fulfilled by MO\&SS in order to support high-quality risk assessments are discussed.

\section{Monitoring and surveillance data and their effect on the risk assessment process}

The type of input data required to conduct risk assessments depends on the underlying decision problem, but in principle, it can be grouped into data for the following steps of the risk assessment process: hazard identification, release assessment, exposure assessment and consequence assessment (Covello \& Merkhofer 1993). Data generated by MO\&SS can be used in all these risk assessment steps (Error! Unknown switch argument.). The second major source of information for risk assessments are targeted epidemiological, toxicological or mi- 
crobiological studies (Roseman 1998), the adequate design of which is important and thus an area with potential for improvement in order to reduce imprecision in risk assessments (Muntd et al. 1998, Younes \& Somich-Mullin 1998).

Hazard identification is the first step in the risk assessment process (Table 1). This step requires a thorough evaluation of existing data and information about the potential hazard to answer the question: "What can go wrong?". Only hazards that are identified will be included in the risk assessment. Hazard identification is therefore a very influential step. Monitoring systems can form the basis for data gathering for the hazard identification. For example, monitoring of antibiotic resistance in animals is used in the assessment of the risk of antibiotic resistance in human medicine. Such a monitoring system is, for example, currently run in Denmark (Anonymous 1998). One hazard under consideration in this country is the use of antibiotics in veterinary medicine, mainly their use as growth promoters. Not all antibiotics that are currently used are identified as hazards at this stage, but depending on the monitoring results in human and animal populations, products other than the ones currently listed by the European Union (EU) (Directive 70/542/EEC with recent amendments) could be phased out. Consequently, MO\&SS can play a major role to determine the final recommendation resulting from a risk assessment process.

The hazard analysis critical control point (HACCP) approach is today used throughout the food processing industry (Hogue et al. 1998). HACCP systems focus on factors (hazards) that have been shown to contribute to foodborne illness. In a second step critical control points are identified. Critical control points are production steps where interventions can be applied. HACCP also includes data recording to monitor the production safety. HACCP systems can therefore be considered to be MO\&SS
(Guzewich et al. 1997). These data can be used in risk assessments and, reciprocally, risk assessment techniques can also be used to develop HACCP programmes (Mayes 1998).

Most frequently, MO\&SS data are used to document the occurrence of agents or substances in the release and exposure assessment part of a risk assessment. With regard to international trade questions, such data are routinely extracted from sources such as the animal health yearbook published by the Office International des Epizooties (OIE, for example, Anonymous 1999a). However, this publication is limited with respect to timeliness and accuracy, as it heavily depends on the quality of veterinary services and the MO\&SS in place in individual countries. Sanson \& Thornton (1997) demonstrated the influence of the quality of surveillance on the time needed for the detection of the first case of a newly introduced disease. Using outbreaks of Salmonella dublin as an example (an exotic agent in the country under consideration), it was shown, that a reduced surveillance programme could increase the median time to diagnosis from 4 weeks to 40 weeks. This demonstrates that background information on the design and conduct of MO\&SS is necessary in order to be able to establish the level of confidence one can have into MO\&SS results. This type of information, however, is not included in the animal health yearbook. It is therefore preferable to obtain data directly from the countries under consideration for import/export.

Regarding endemic diseases, monitoring of strain differences can also be a useful tool for the release assessment step of the risk assessment process. This is particularly important if differences between countries exist. For example, in Denmark the current monitoring system with respect to Salmonella enterica in swine includes strain differentiation. All salmonella isolates are phage-typed and a stamping-out strategy was adopted for multiresistant Salmonella 
enterica Typhimurium DT104 (Møgelmose et al. 1999). Imported commodities that contain multiresistant Salmonella enterica Typhimurium DT104 are no longer acceptable. This decision is based on the zero prevalence of multiresistant Salmonella enterica Typhimurium DT104 in food in Denmark and the health risk posed by this strain to affected humans. If strain differences in Denmark were not monitored, there would be no basis for applying such specific risk management strategies.

With respect to toxic substances and residues in food, MO\&SS are being maintained in many countries. MO\&SS for zoonotic agents, on the other hand, have gained attention only in recent years and mainly in Scandinavian countries. Additionally, the systems that are in place for residue and zoonotic agent monitoring are almost exclusively based on end product control. Monitoring of the entire production chain, however, is necessary for risk management measures such as the development of HACCP systems (Hathaway 1993). Such systems require the herd of origin to be integrated in the monitoring process (Blaha 1999). Integrated programs of this kind are only very rarely implemented. One example is the Salmonella enterica reduction programme in Denmark (Nielsen \& Wegener 1997).

\section{Ensuring high-quality input for risk assessments}

Quality of data is dependent on the methods and procedures used for data collection (Younes \& Somich-Mullin 1998). All MO\&SS should therefore include quality assurance steps. The validity determinants of a MO\&SS are similar to those of any epidemiological study, namely proper study design, adequate sample size, representative samples, unbiased measure of outcome, control for confounding factors and correct statistical analysis (Mundt et al. 1998). Additionally, there are some analytical issues that are specific for animal populations. For example, animal populations are typically aggregated and mobile and consequently, disease can occur in clusters in time and space (Salman \& Ruppanner 1999). A series of articles addressing these analytical issues have recently been published (for example, Donald et al. 1994, Dargatz \& Hill 1996, Cameron \& Baldock 1998a, 1998b, Audigé \& Beckett 1999), but the transfer of scientific knowledge to routine data collection has yet to occur. The new principles for sampling (e.g. cluster sampling) and analysis need to be integrated in national MO\&SS legislation as well as in international MO\&SS guidelines, for example, in the International Animal Health Code (Anonymous 1999b).

Clearly, there are many different types of MO\&SS and there is no easy way to assess their quality. Nevertheless there is a need to evaluate MO\&SS according to specific criteria in order to be able to interpret data correctly (Welte et al. 1998, Anonymous 1999c). Hueston (1993) suggested that the ideal national MO\&SS should include aspects for the surveillance of disease agents, for host monitoring (e.g. livestock population census) and environmental assessments. Based on this principle, he suggested a catalogue of criteria to assess the level of implementation of MO\&SS and the quality of veterinary services in a country. The issue of MO\&SS evaluation was recently further contemplated by Dufour (1999). This author suggested the use of critical control points similar to an HACCP assessment to evaluate the quality of a MO\&SS. Suggested critical control points were, for example, sampling, co-ordination and awareness, screening and diagnosis, as well as data collection, recording and analysis. This method was successfully applied to three existing surveillance systems. Based on the evaluation, recommendations were given in order to improve the quality of the programmes. These two examples document the need for a 
quality assessment of MO\&SS. If MO\&SS were designed according to accepted standards, the data produced by these programmes would be of comparable quality and could be more readily used in risk assessments. In an additional step, MO\&SS applying accepted standards could even be 'certified' by an independent organisation such as the OIE.

In order to provide better and higher quality input for risk assessments, MO\&SS also need to be designed with the application of the data in mind. Therefore, people involved in data collection and analysis should not only know about survey design, but also have a basic understanding of risk assessment and the respective data needs (Younes \& Somich-Mullin 1998).

\section{Discussion and conclusions}

Risk assessment as a scientific framework is being promoted in the international trade and the food safety arena by the World Trade Organisation (Campos 1998), the OIE, the Codex Alimentarius Commission and the EU. These organisations are recognising the need for good quality data input and are promoting MO\&SS as data sources. For example, the EU has listed the need for monitoring systems in a recent resolution for an antibiotic resistance strategy (Anonymous 1999d). Similarly, the OIE writes in the latest edition of the International Animal Health Code (1999b) that each country that plans to export animals or animal products needs to supply information on its MO\&SSHYPERLINK. This is necessary for the importing country to review the evidence for freedom from disease and to assess the related risk (Welte et al. 1998). The OIE has also developed standards for the surveillance of rinderpest and contagious bovine pleuropneumonia (http:// www.oie.int/Norms/a_surv.htm), and standards regarding other diseases are likely to follow.

As MO\&SS are to be used as data sources for risk assessments the quality of the data pro- vided needs to be known. The validity of data consists of both internal and external validity. An assessment of data validity is suggested to be part of every MO\&SS. This issue becomes even more pressing if data are to be used in risk assessments that need to be justifiable in the international trade arena. If minimal standards for MO\&SS were specified, risk assessments could be readily compared between countries. This would support harmonisation of trade, one of the key objectives of the Sanitary and Phytosanitary Agreement governed by the World Trade Organisation. In the long term, even a certification of MO\&SS could be envisaged.

The analysis of data generated by MO\&SS or a survey is not always straightforward and specific issues have to be addressed. Although progress is being made in this area, the work remains largely limited to academic exercises and is not yet widely applied. In order to improve the knowledge transfer from research to application, scientific results have to be translated into practical examples, and user-friendly software tools need to be developed for field use.

Finally, everybody involved with the development of MO\&SS, with data collection and analysis should have a basic understanding of the risk assessment process in order to appreciate the significance of data quality. Also feedback of risk assessment results to MO\&SS staff needs to be strengthened. It has been shown in many examples that this increases motivation among data collectors and thus indirectly improves data quality.

The use of MO\&SS data for risk assessment will ultimately support risk management, i.e. the selection and implementation of risk reduction measures. After risk reduction measures are implemented, MO\&SS can again be used to measure the efficacy of these interventions. This is very much according to the original aim of surveillance, namely to provide information for action (Thacker \& Gregg 1996). 


\section{References}

Anonymous: DANMAP 97 - Consumption of antimicrobial agents and occurrence of antimicrobial resistance in bacteria from food animals, food and humans in Denmark. Danish Zoonosis Centre, Copenhagen, Denmark, 1998.

Anonymous: World animal health. Office International des Epizooties, Paris, 1999a.

Anonymous: International Animal Health Code. $8^{\text {th }}$ Edition. Office International des Epizooties, Paris, 1999b, http://www.oie.int.

Anonymous: Summary of the 1998 animal health monitoring and surveillance work conference. USDA:APHIS:VS 1999c.

Anonymous: Council resolution of 8 June 1999 on antibiotic resistance 'A strategy against the microbial threat' (1999/C 195/01). Offic. J. Europ. Comm. 13.7.1999d, C195, 1-3

Ahl AS, Scree PS, Gipson PS, McDowell RM, Miller $L$, McElvaine MD: Standardization of nomenclature for animal health risk analysis. Rev. Sci. Tech. Off. Int. Epiz. 1993, 12, 1045-1053.

Audigé L, Beckett $S$ : A quantitative assessment of the validity of animal-health surveys using stochastic modelling. Prev. Vet. Med. 1999, 38, 259-276.

Blaha T: Epidemiology and quality assurance application to food safety. Prev. Vet. Med. 1999, 39, 81-92.

Cameron AR, Baldock FC: A new probability formula for surveys to substantiate freedom from disease. Prev.Vet.Med. 1998a, 34, 1-17.

Cameron AR, Baldock FC: Two-stage sampling in surveys to substantiate freedom from disease. Prev.Vet.Med. 1998b, 34, 19-30.

Covello VT, Merkhofer MW: Risk Assessment Methods - Approaches for Assessing Health and Environmental Risks. Plenum Press, New York, 1993.

Campos H: The ten commandments of the Sanitary and Phytosanitary Agreement of the World Trade Organization. Working paper, $2^{\text {nd }}$ FAO E-Conference on Veterinary Services 1998, http://www. fao.org/ag/aga/agah/Vets-1-2/Contents/ Default.htm.

Christensen J: Epidemiological concepts regarding disease monitoring and surveillance. Acta vet. Scand. (submitted).

Dargatz DS, Hill GW: Analysis of survey data. Prev. Vet. Med. 1996, 28, 225-237.

Donald AW, Gardner IA, Wiggins AD: Cut-off points for aggregate herd testing in the presence of disease clustering and correlation of test errors.
Prev. Vet. Med. 1994, 19, 167-87.

Dufour B: Technical and economic evaluation method for use in improving infectious animal disease surveillance networks. Vet. Res. 1999, 30, 27-37.

Guzewich JJ, Bryan FL, Todd ECD: Surveillance of foodborne disease: I. purposes and types of surveillance systems and networks. J. Food Prot. 1997, 60, 555-566

Hathaway SC: Risk analysis and meat hygiene. Rev. Sci. Tech. Off. Int. Epiz. 1993, 12, 1265-1290.

Hogue AT, White PL, Heminover JA: Pathogen reduction and hazard analysis and critical control point (HACCP) systems for meat and poultry. Vet.Clin.North Am. Food Anim.Pract. 1998, 14, 151-164.

Hueston WD: Assessment of national systems for the surveillance and monitoring of animal health. Rev. sci. tech. Off. int. Epiz. 1993, 12, 1187-96.

Kaplan S, Garrick BJ: On the quantitative definition of risk. Risk Anal. 1981, 1, 11-27.

Mayes T: Risk analysis in HACCP: burden or benefit? Food Control 1998, 9, 171-175.

Mundt KA, Tritschler, JP, Dell, LD: Validity of epidemiological data in risk assessment applications. Hum. Ecol. Risk Assess. 1998, 4, 675-683.

Møgelmose V, Nielsen B, Sørensen LL, Dahl J, Wingstrand A, Johansen M, Pihl K, Nielsen V, Svensmark B, Udesen F, Larsen LP, Baggesen $D L$ : Eradication of multiresistant Salmonlla Typhimurium DT104 infections in 15 Danish swine herds. Proc. $3^{\text {rd }}$ Int. Symp. Epid. Contr. Salm. Pork, Washington, 1999, 367-369.

Nielsen B, Wegener HC: Public health and pork and pork products: regional perspectives of Denmark. Rev. sci. tech. Off. int. Epiz. 1997, 16, 513-24.

Roseman JM: What can be done to ensure the usefulness of epidemiologic data for risk assessment purposes? Hum. Ecol. Risk Assess. 1998, 4, 737746.

Sanson RL, Thornton $R N$ : A modelling approach to the quantification of the benefits of a national surveillance programme. Prev. Vet. Med. 1997, 30, 37-47.

Salman M, Ruppaner R: Risk management and decision analysis in animal health. Proc. Ann. Conf. Soc. Vet. Epid. Prev. Med., Bristol 1999, 1-6.

Thacker SB, Gregg MB: Implementing the concepts of William Farr: the contributions of Alexander D. Langmuir to public health surveillance and communications. Americ. J. Epidemiol. 1996, 144 (Suppl), 23-8. 
Welte VR, Otte J, Ward D: Supporting claims of freedom from disease. Working paper, $2^{\text {nd }} F A O$ EConference on Veterinary Services 1998, http:// www.fao.org/ag/aga/agah/Vets-1-2/Contents/Default.htm.
Wooldridge M: Risk analysis, risk assessment, animal health and the decision-making process. State Vet. J. 1996, 12, 4-6.

Younes M, Sonich-Mullin, C: Reducing imprecision in risk assessment - A plea for focused science. Hum. Ecol. Risk Assess. 1998, 4, 259-262. 